\title{
Visible-Light Degradation of Dyes and Phenols over Mesoporous Titania Prepared by Using Anthocyanin from Red Radish as Template
}

\author{
Zhiying Yan, Wenjuan Gong, Yongjuan Chen, Deliang Duan, Junjie Li, \\ Wei Wang, and Jiaqiang Wang \\ Department of Applied Chemistry, Key Laboratory of Medicinal Chemistry for Natural Resource, Ministry of Education, \\ Yunnan University, Kunming 650091, China
}

Correspondence should be addressed to Jiaqiang Wang; jqwang@ynu.edu.cn

Received 7 July 2014; Accepted 20 August 2014; Published 2 September 2014

Academic Editor: Wenjun Luo

Copyright (C) 2014 Zhiying Yan et al. This is an open access article distributed under the Creative Commons Attribution License, which permits unrestricted use, distribution, and reproduction in any medium, provided the original work is properly cited.

\begin{abstract}
Heterogeneous photocatalysis is able to operate effectively to eliminate organic compounds from wastewater in the presence of semiconductor photocatalyst and a light source. Although photosensitization of titania by organic dyes is one of the conventional ways for visible-light utilization of titania, previous studies have not yet addressed the use of natural food coloring agents as templates in the synthesis of mesostructured materials, let alone the simultaneous achievement of highly crystalline mesoscopic framework and visible-light photocatalytic activity. In this work, anthocyanin, a natural pigment from red radish was directly used as template in synthesis of highly crystalline mesoporous titania. The synthesized mesoporous titania samples were characterized by a combination of various physicochemical techniques, such as XRD, SEM, HRTEM, nitrogen adsorption/desorption, and diffuse reflectance UV-Vis. The prepared mesoporous titania photocatalyst exhibited significant activity under visible-light irradiation for the degradation of dyes and phenols due to its red shift of band-gap-absorption onset and visible-light response as a result of the incorporation of surface carbon species.
\end{abstract}

\section{Introduction}

Organic dyes and phenolic compounds usually come from industrial effluent and other artificial activities and are very toxic compounds which contribute significantly to water pollution. Elimination of these organic compounds from wastewater using heterogeneous photocatalysis which are able to operate effectively in the presence of semiconductor photocatalytic materials and a light source appears as the most emerging destructive technology [1]. Most of the semiconductor materials reported in the literature as photocatalysts are based on $\mathrm{TiO}_{2}$ because of its low price and steady and high photocatalytic activation. Unfortunately, the wide band gap of pristine $\mathrm{TiO}_{2}$ limits its light absorption only to the UV-light range and $97 \%$ of the visible spectra of sunlight reaching the surface of earth are unable to be used by $\mathrm{TiO}_{2}$, which hold back its practical applications. Therefore, many researchers are focusing on how to modify the quality of
$\mathrm{TiO}_{2}$ to improve the efficiency of $\mathrm{TiO}_{2}$ to absorb visible light $[2,3]$. Photosensitization of $\mathrm{TiO}_{2}$ nanoparticles by organic dyes was found to be an effective approach to enhance the visible-light utilization of $\mathrm{TiO}_{2}$, because organic dye molecules attached to the surface of $\mathrm{TiO}_{2}$ are responsible for absorbing the incoming light [4-6]. For example, Chowdhury et al. [6] have used eosin $\mathrm{Y}$ dye as a sensitizer to prepare visible-light-active $\mathrm{TiO}_{2}$ catalyst and found that about $93 \%$ degradation of $40 \mathrm{ppm}$ phenol solution was achieved within 90 min using eosin $\mathrm{Y}^{-\mathrm{TiO}_{2}} / \mathrm{Pt}$ photocatalyst under visible solar light. Recently, natural dyes extracted from flowers, leaves, fruits, and beverages have become a viable alternative to expensive or toxic organic sensitizers because of their low cost, easy attainability, abundance in supply of raw materials, and no environment threat [7-9]. Among them, anthocyanins are naturally occurring compounds that are responsible for the coloration of flowers, fruits, fruit juice, wines, leaves, stems, bulbs, roots, and so forth. They are also 
<smiles></smiles>

FIGURE 1: The structural formula of radish red pigment.

the most important group of visible plant pigments besides chlorophyll and show a broad absorption band in the range of visible light. Therefore, anthocyanins often are used as natural dye sensitizers of wide band gap semiconductors. Calogero et al. [10] extracted anthocyanin natural dyes from Clitoria ternatea as sensitizer of dye sensitized solar cells and absorption spectra of Clitoria ternatea sensitized nanocrystalline $\mathrm{TiO}_{2}$ thin films show a small shift towards longer wavelength side. Zyoud et al. [11] have successfully used as them a safe alternative sensitizer in photodegradation of organic water contaminant catalyzed by $\mathrm{TiO}_{2}$ particles. However, these dye-sensitized $\mathrm{TiO}_{2}$ catalysts suffer from poor stability due to the thermal or photochemical decomposition of dyes and weak binding energy between the $\mathrm{TiO}_{2}$ and dyes.

What is interesting is that Faul and Antonietti [12] have developed a facile method to synthesize an optically functional, organic composite material by simple precipitation of charged dyes with oppositely charged surfactants. Recently, $\mathrm{Xu}$ et al. [13] have also prepared mesoporous silica by using basic fuchsin as template and methylene diisocyanate or aminopropyltriethoxysilane as bridging molecules. More recently, in our group chrome azurol S [14] and even commercial synthetic dyes [15] have been successfully used as templates in synthesis of mesoporous anatase $\mathrm{TiO}_{2}$, shifting the absorption edge of $\mathrm{TiO}_{2}$ to the visible-light range, narrowing the band gap, and resulting in strong absorption in the visible region. The prepared $\mathrm{TiO}_{2}$ exhibited significant photocatalytic activity in the degradation of four dyes, gentian violet, methyl violet, rhodamine $B$, and methylthionine chloride under solar light irradiation.

Herein, in the continuation of our work, we further investigated the synthesis and its photocatalytic activity of mesoporous titania templated by anthocyanin from red radish (Raphanus sativus L.), an edible red shell, and heart radish which have a long planting history locally. Here, we call it the radish red pigment. The main ingredient of radish red pigment is pelargonidin derivative which belongs to one of the most widespread anthocyanin. The structural formula for pelargonidin is pelargonidin-3-sophoroside, 5glucoside structure $[16,17]$ as shown in Figure 1 . The prepared mesoporous $\mathrm{TiO}_{2}$ was evaluated by the degradation of three dyes such as methylthionine chloride, gentian violet, and rhodamine $\mathrm{B}$ and two phenolic compounds including phenol and 2, 4-dichlorophenol under visible light. Besides, other food dyes with different structural forms, such as purple sweet potato color, safflower yellow, and gardenia blue pigment, were also used as templates to prepare $\mathrm{TiO}_{2}$ aimed at investigating contrastively the influence of template structure on photocatalytic activities of $\mathrm{TiO}_{2}$. Our works imply that anthocyanin from red radish could be potential template for direct synthesis of highly crystalline mesoporous titania with visible-light photocatalytic activity to degrade organic contaminants. To the best of our knowledge, there is no report on using natural pigments as a template for synthesis of mesoporous materials, let alone the simultaneous achievement of highly crystalline mesoscopic frameworks and visible-light photocatalytic activity. In particular, the prepared mesoporous $\mathrm{TiO}_{2}$ show good activity in the phenol degradation under visible-light irradiation, which have not yet studied in our previous reports $[14,15]$.

\section{Materials and Methods}

\subsection{Materials}

2.1.1. Chemicals. All chemicals such as titanium isopropoxide $\mathrm{Ti}\left[\mathrm{OCH}\left(\mathrm{CH}_{3}\right)_{2}\right]_{4}$, three dyes including methylthionine chloride (MC), rhodamine B (RB), and gentian violet (GV) and two phenolic compounds including phenol and 2, 4dichlorophenol were used without further purification and all of them were analytical reagents.

2.1.2. Natural Food Coloring Agents. All pigments were kindly provided by Yunnan Tonghai Yang Natural Products Co., LTD. (a) Radish red pigment (RRP) was extracted from Raphanus sativus L., an edible red shell and heart radish which have a long planting history locally. The process was checked, washed, sliced, extracted, filtrated, purified, concentrated, sterilized, sprayed, and dried. The main ingredient is anthocyanidin which contains pelargonidin. (b) Purple sweet potato color (PSPC) was extracted from purple root tuber of edible sweet potato (Impomoea batatas) planted locally. The process was checked, washed, sliced, extracted, filtrated, purified, concentrated, sterilized, sprayed, and dried. The main coloring ingredient is cyaniding acyl glucoside and peonidin acyl glucoside. (c) Safflower yellow (SY) was extracted from the petal of Carthamus tinctorius, by the process of extracting, filtrating, purifying, concentrating, sterilizing, spraying, and drying. The main ingredient is carthamin yellow. (d) Gardenia blue (GB) was obtained by amination of genipin which was formed by hydrolysis of colorless geniposide from the gardenia fruit of madder family by biological fermentation.

2.2. Preparation of Mesoporous $\mathrm{TiO}_{2}$. In a typical preparation process of $1.0 \mathrm{~g}$ radish red pigment was dissolved in $30 \mathrm{~mL}$ ethanol under stirring, and $3.0 \mathrm{~g}$ titanium isopropoxide $\mathrm{Ti}\left[\mathrm{OCH}\left(\mathrm{CH}_{3}\right)_{2}\right]_{4}$ was added slowly until the solution became a clear gel. Then $60 \mathrm{~mL}$ water was added dropwise under continuous stirring, which caused the immediate precipitation of a solid. Subsequently, the final mixture was stirred for $24 \mathrm{~h}$ and then transferred into a Teflon bottle and treated under autogenous pressure at $363 \mathrm{~K}$ for 7 days, filtered, washed, dried, and calcined at $673 \mathrm{~K}$ in air for $6 \mathrm{~h}$. Finally lightyellow powder was obtained. The samples are designated 
as $\mathrm{MTiO}_{2} / \mathrm{RRP}$. Following the same procedure as preparing $\mathrm{MTiO}_{2} / \mathrm{RRP}$, other mesoporous $\mathrm{TiO}_{2}$ catalyst prepared by using purple sweet potato color, safflower yellow, and gardenia blue pigment as templates are called $\mathrm{MTiO}_{2} / \mathrm{PSPC}$, $\mathrm{MTiO}_{2} / \mathrm{SY}$, and $\mathrm{MTiO}_{2} / \mathrm{GB}$, respectively.

2.3. Characterization. X-ray powder diffraction (XRD) experiments were conducted on a $\mathrm{D} / \max -3 \mathrm{~B}$ spectrometer with $\mathrm{Cu} \mathrm{K} \alpha$ radiation. Scans were made in the $2 \theta$ range $0.5-5^{\circ}$ with a scan rate of $0.02^{\circ} / \mathrm{min}$ (low angle diffraction) and in the $2 \theta$ range $10-90^{\circ}$ with a scan rate of $10^{\circ} / \mathrm{min}$ (wide angle diffraction). High-resolution transmission electron microscopy (HRTEM) images were taken on a TEM (JEOL200CX). Pore size distributions, BET surface areas, and pore volumes were measured by nitrogen adsorption/desorption using a NOVA 2000e gas sorption analyzer (Quantachrome Corp.). Prior to the analysis, the samples were degassed at $150^{\circ} \mathrm{C}$ for $1 \mathrm{~h}$. UV-Vis diffuse reflectance spectra were measured at room temperature in air on a Shimadzu UV2401PC photometer over the range from 200 to $800 \mathrm{~nm}$. FT-IR measurements were performed on a Thermo Nicolet 8700 instrument. Potassium bromide pellets containing $0.5 \%$ of the catalysts were used in FT-IR experiments and 32 scans were accumulated for each spectrum in transmission, at a spectral resolution of $4 \mathrm{~cm}^{-1}$. The spectrum of dry $\mathrm{KBr}$ was taken for background subtraction. X-ray photoelectron spectra (XPS) measurement was performed on a PHI5000VersaProbe II analyzer.

2.4. Evaluation of Photocatalytic Activity. The reactions of the photocatalytic degradation of dyes and phenolic compounds were carried out in a glass batch photoreactor containing $50 \mathrm{~mL}$ of a $10 \mathrm{ppm}$ model solution and $25 \mathrm{mg}$ of photocatalyst. The suspensions were magnetically stirred in dark for $24 \mathrm{~h}$ to attain adsorption-desorption equilibrium between dyes and mesoporous $\mathrm{TiO}_{2}$. The decrease due to adsorption can be deducted after the adsorption equilibrium was achieved. After $24 \mathrm{~h}$ in the dark, the reactor was illuminated with a $500 \mathrm{~W}$ tungsten lamp. A combination of two filters, VISNIR long pass filter $(400 \mathrm{~nm})$ and a coloured glass filter $(>420 \mathrm{~nm})$, was utilized for the purpose of allowing only visible-light radiation. Samples were analyzed after centrifugation (1500 rpm for $10 \mathrm{~min})$. The color removal of the dye solution was measured by Shimadzu UV-2401PC photometer over the range from 400 to $800 \mathrm{~nm}$.

\section{Results and Discussion}

3.1. Structure and Morphology of Mesoporous Titania. The XRD patterns of $\mathrm{MTiO}_{2} / \mathrm{RRP}$ prepared by using radish red pigment as a template, shown in Figure 2, demonstrates clearly that the sample is highly crystallized and could be indexed to titania of the anatase phase (JCPDS card number 04-0477). No other diffraction is observed, suggesting a pure anatase phase. Detailed analysis of the peak broadening of the $\left(\begin{array}{lll}1 & 0 & 1\end{array}\right)$ reflection using the Scherrer equation indicates an average crystallite size of ca. $8 \mathrm{~nm}$, indicating that the anatase $\mathrm{TiO}_{2}$ particles are composed of nanocrystal subunits.

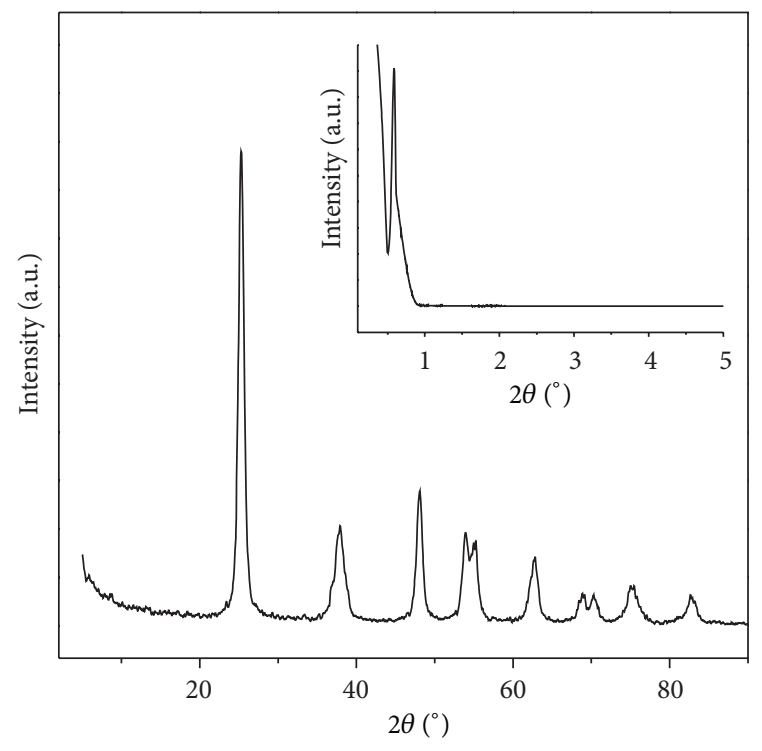

Figure 2: XRD wide and small angle patterns of $\mathrm{MTiO}_{2} / \mathrm{RRP}$.

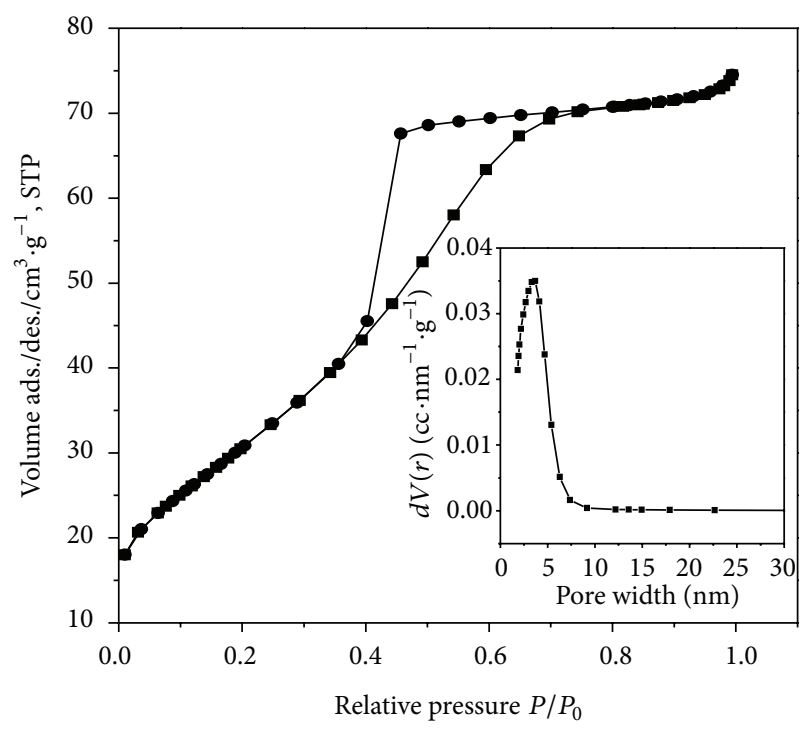

FIGURE 3: Nitrogen adsorption-desorption isotherm of $\mathrm{MTiO}_{2} / \mathrm{RRP}$. $\mathrm{BJH}$ pore size distributions are shown in the inset.

Moreover, the small-angle peak at around $0.8^{\circ}$ in $2 \theta$ (inset in Figure 2) corresponds to the internanoparticle separations of $12.6 \mathrm{~nm}$, suggesting that the materials lack long-range ordered arrangements. This is coincident with the results in the literatures $[18,19]$.

The $\mathrm{N}_{2}$ adsorption/desorption isotherms and the pore size distribution of the obtained $\mathrm{MTiO}_{2} / \mathrm{RRP}$ are shown in Figure 3. This hysteresis shows an IV-type hysteresis loop in the $P / P_{0}$ range from 0.40 to 0.8 , a characteristic of titania type mesoporous materials. The BET surface area and pore diameter of the sample are $112 \mathrm{~m}^{2} \cdot \mathrm{g}^{-1}$ and $3.3 \mathrm{~nm}$, respectively. This phenomenon is in good agreement with those mesoporous $\mathrm{TiO}_{2}$ templated by other templates, such as block copolymers or surfactants. Typical mesoporous 


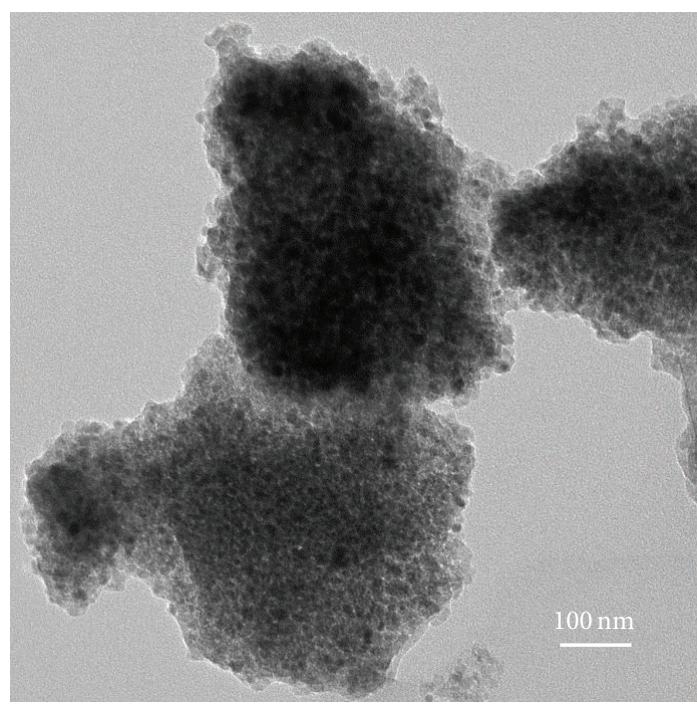

(a)

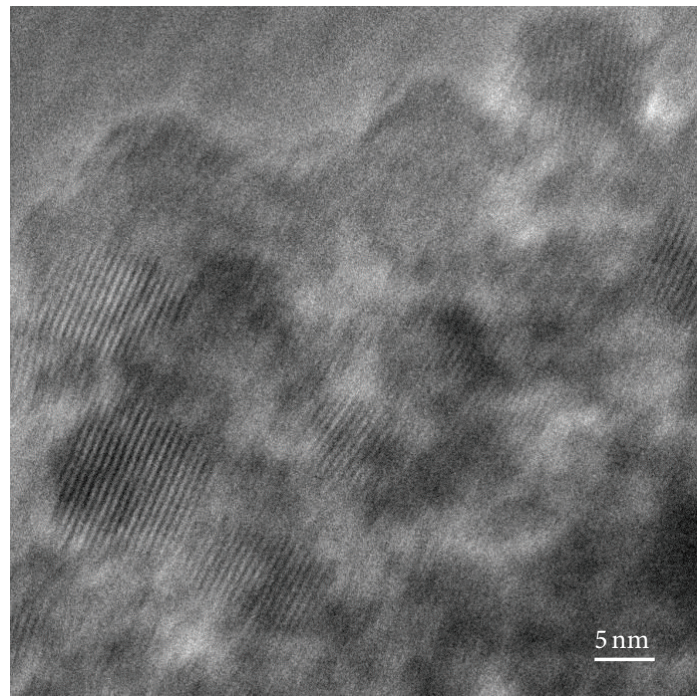

(c)

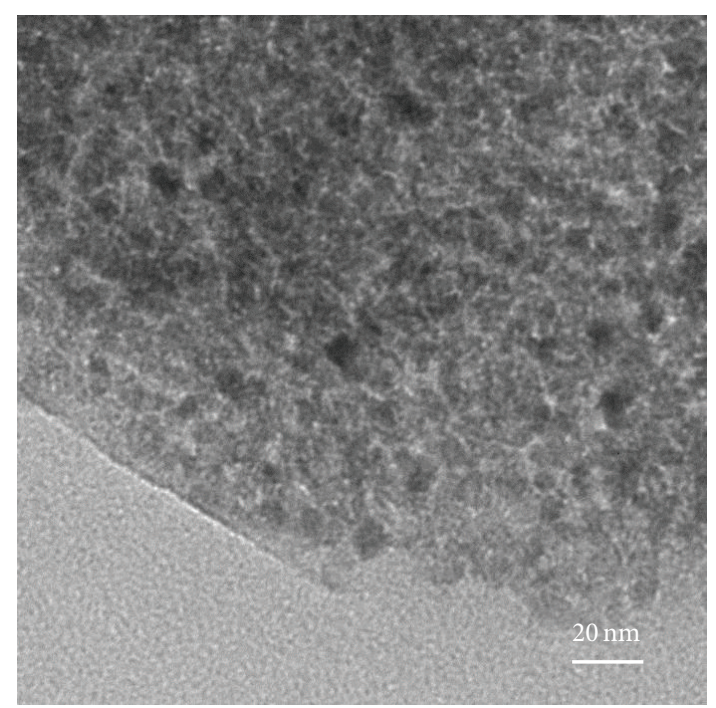

(b)

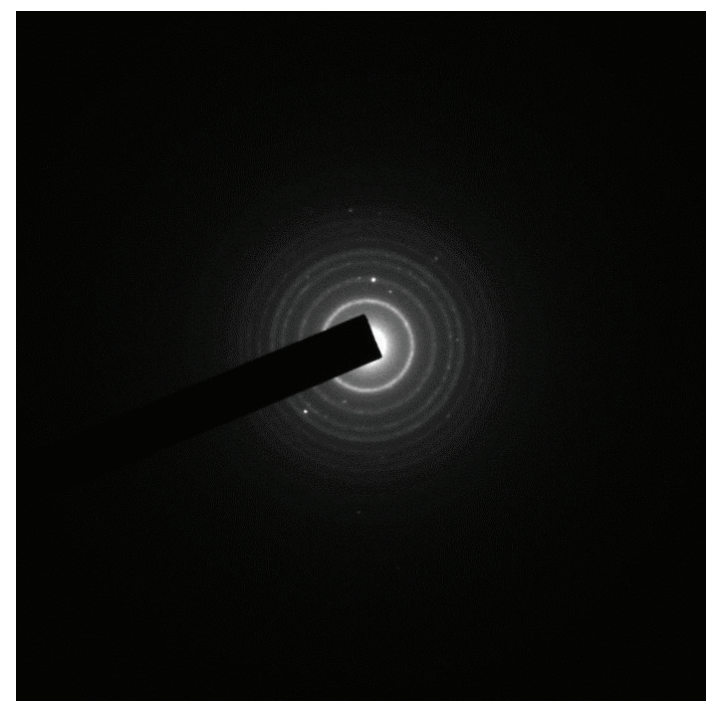

(d)

Figure 4: TEM ((a) and (b)), HRTEM (c) images, and ED (d) of $\mathrm{MTiO}_{2} / \mathrm{RRP}$

titania prepared by using dodecylamine as templates shows highly aggregated and nonuniform structure [20]. TEM image presented in Figure 4(a) shows the morphology of $\mathrm{MTiO}_{2} / \mathrm{RRP}$. By contrast, $\mathrm{MTiO}_{2} / \mathrm{RRP}$ particles are reasonably uniform in size of $200 \mathrm{~nm}$. Moreover, direct evidence for the existence of mesopores with highly crystalline and orderly wormhole frameworks has been obtained from TEM images and selected area electron diffraction pattern shown in Figures 4(b), 4(c), and 4(d), respectively. Therefore, $\mathrm{N}_{2}$ adsorption/desorption isotherms, XRD, and TEM are all similar to those of mesoporous $\mathrm{TiO}_{2}$ templated by block copolymers or surfactants [21] or commercial synthetic dyes previously used by us [15].

3.2. Photocatalytic Activity of Mesoporous $\mathrm{TiO}_{2}$. The photoactivities of the synthesized samples were evaluated by the degradation of dyes and phenolic compounds including
MC, RB, GV, phenol, and 2, 4-dichlorophenol under visible light. In order to obtain the real photodegradation yield due to the photocatalysis in the presence of photocatalysts, the decreases of the contaminants concentration because of the adsorption and direct photolysis should be deducted. The photodegradation yield was calculated by the following equation [22]:

$$
\text { Photodegradation yield }=\frac{\left(C_{o}-C_{a}-C_{b}\right)}{C_{o}} \times 100 .
$$

$C_{o}$ is the initial concentration of contaminants, $C_{a}$ is the concentration after photodegradation of contaminants, and $C_{b}$ is the decreased concentration because of the direct photolysis.

Based on the above definition, the comparison of their photodegradation yields for the degradation of three dyes under visible-light irradiation is shown in Figure 5. It is noted 


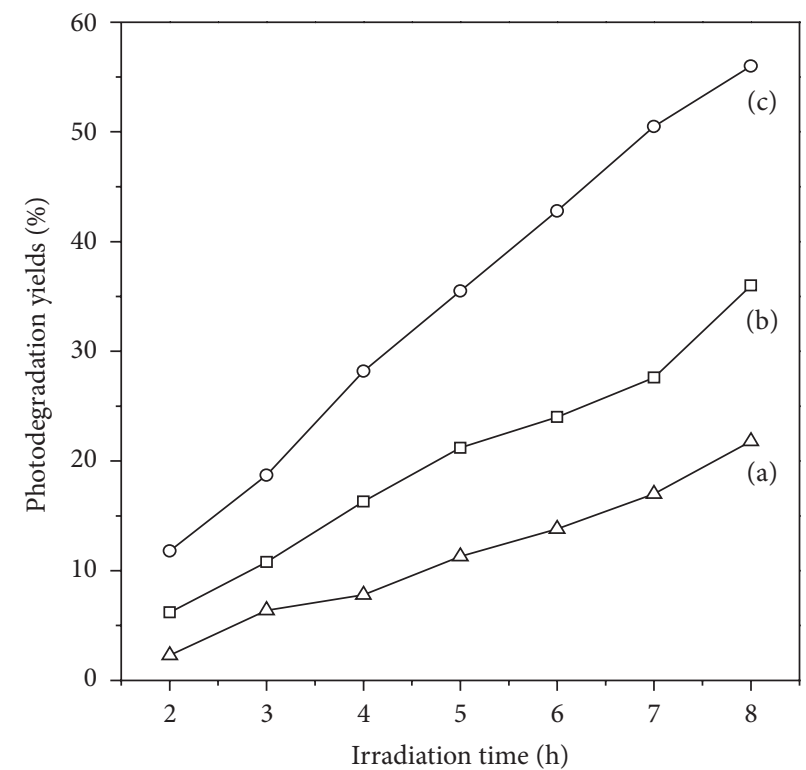

FIGURE 5: Photodegradation yields of methylthionine chloride (a), rhodamine B (b), and gentian violet (c) over $\mathrm{MTiO}_{2} / \mathrm{RRP}$ under visiblelight irradiation $(\lambda>420 \mathrm{~nm})$.

that the photodegradation yields increased sharply with the exposure time, and $20 \%, 34.9 \%$, and $56.2 \%$ of MC, RB, and GV were degraded within $8 \mathrm{~h}$, respectively. The results suggest that some dyes, especially RB, could be degraded effectively by $\mathrm{MTiO}_{2} / \mathrm{RRP}$. Such behavior has not been observed when the commercial Degussa $\mathrm{P} 25 \mathrm{TiO}_{2}$ was used. As is known to all, $\mathrm{P} 25 \mathrm{TiO}_{2}$ does not exhibit any meaningful activity for the degradation of RB with visible light even though it exhibits photodegradation yield of $\sim 87 \%$ with UV light. More interestingly, it was found in Figure 6 that the photocatalytic activity of $\mathrm{MTiO}_{2} / \mathrm{RRP}$ for phenolic compounds was higher than that for dyes and the photodegradation yields of phenol and 2, 4-dichlorophenol are up to $54 \%, 65 \%$ after $4 \mathrm{~h}$ visiblelight irradiation, respectively. By contrast, Degussa $\mathrm{P} 25 \mathrm{TiO}_{2}$ had no any photocatalysis for degradation of the two phenolic compounds.

The success in synthesis of $\mathrm{MTiO}_{2} / \mathrm{RRP}$ by using RRP as a template and its unusual visible-light activity of $\mathrm{MTiO}_{2} / \mathrm{RRP}$ encouraged us to extend this method to other natural pigments. Following the same procedure as preparing $\mathrm{MTiO}_{2} / \mathrm{RRP}$, safflower yellow (SY), purple sweet potato color (PSPC), and gardenia blue pigment (GB) were used as templates to prepare mesoporous titania called $\mathrm{MTiO}_{2} / \mathrm{PSPC}$, $\mathrm{MTiO}_{2} / \mathrm{SY}$, and $\mathrm{MTiO}_{2} / \mathrm{GB}$, respectively. In the selected pigments, PSPC is an acylated anthocyanidin and SY belongs to chalcone group with the same type $\mathrm{C} 6-\mathrm{C} 3-\mathrm{C} 6$ backbone structure as anthocyanidin, whereas $\mathrm{GB}$ is a rare natural blue pigment with iridoid base structure. The structure of pigments [23-25] and the results of $\mathrm{MTiO}_{2} / \mathrm{PSPC}, \mathrm{MTiO}_{2} / \mathrm{SY}$, and $\mathrm{MTiO}_{2} / \mathrm{GB}$ to degrade $\mathrm{RB}$ and phenol under visiblelight irradiation are summarized in Table 1. It can be found that the photodegradation yields of $\mathrm{RB}$ over $\mathrm{MTiO}_{2} / \mathrm{PSPC}$ and $\mathrm{MTiO}_{2} / \mathrm{SY}$ are $26.7 \%$ and $31.2 \%$ within $8 \mathrm{~h}$, respectively, whereas $\mathrm{MTiO}_{2} / \mathrm{GB}$ is only $4.6 \%$ of photodegradation to

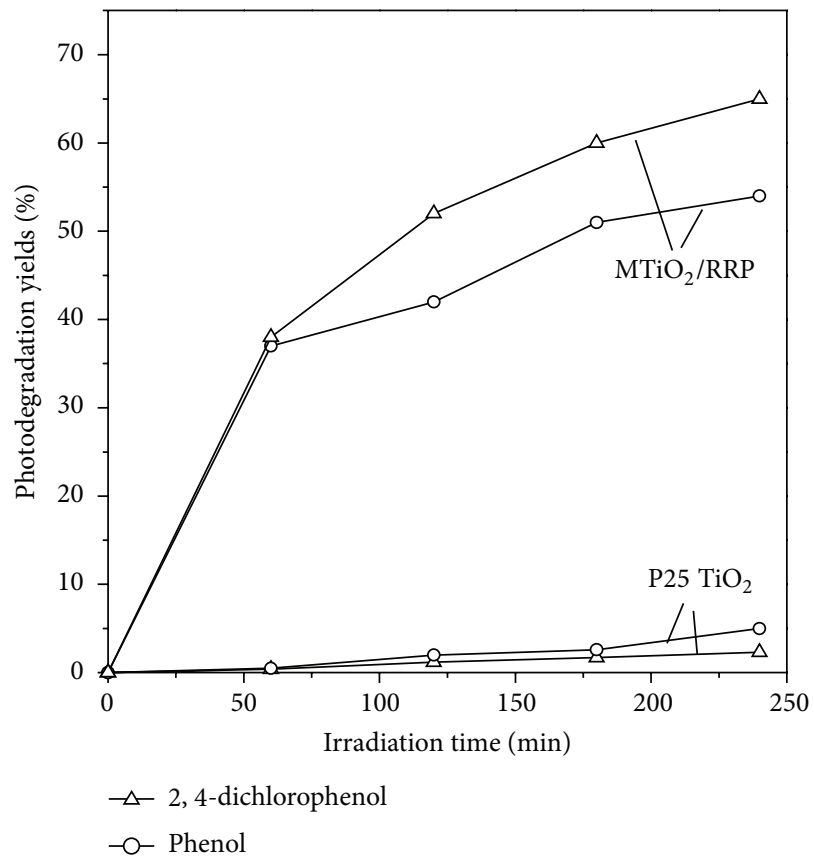

FIGURE 6: Photodegradation yields for degradation of phenol and 2, 4-dichlorophenol over $\mathrm{MTiO}_{2} / \mathrm{RRP}$ and $\mathrm{P} 25 \mathrm{TiO}_{2}$ under visiblelight irradiation $(\lambda>420 \mathrm{~nm})$.

$\mathrm{RB}$ and is slightly better than commercial Degussa P25 $\mathrm{TiO}_{2}$ on visible light activity. By contrast, only $\mathrm{MTiO}_{2} / \mathrm{PSPC}$ shows $29.8 \%$ of photodegradation yields after $4 \mathrm{~h}$ visible-light irradiation.

From Table 1, Figures 5 and 6 , we find that $\mathrm{TiO}_{2}$ prepared by RRP, PSPC, and SY with the C6-C3-C6 backbone structure shows the visible-light activity for RB. Furthermore, 
TABle 1: Summary of photodegradation yields for degradation of RB and phenol under visible-light irradiation over $\mathrm{MTiO}_{2}$ samples synthesized by using different natural pigments as template.

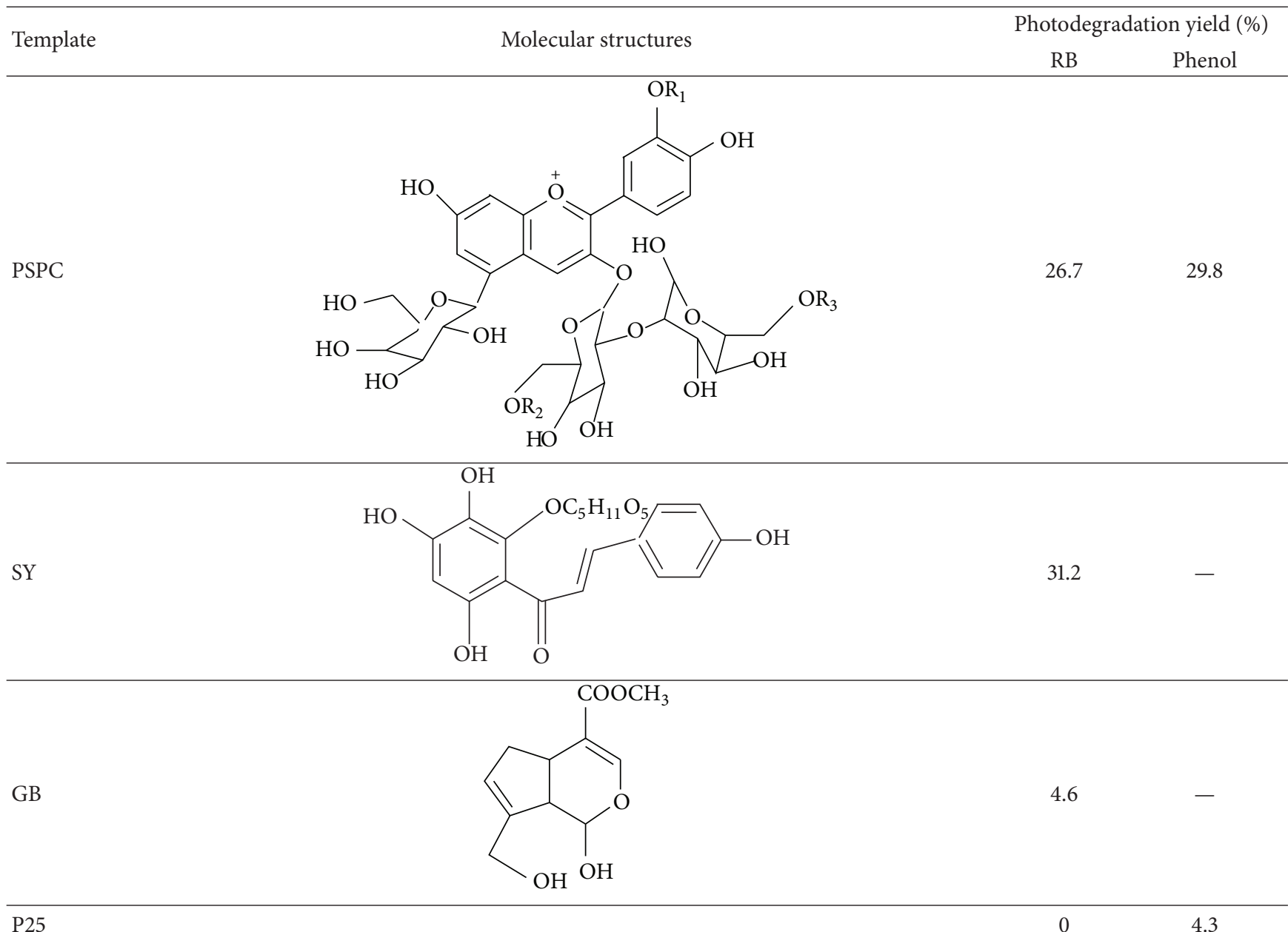

$\mathrm{TiO}_{2}$ prepared by RRP and PSPC of anthocyanin have more obvious catalyzed effect on phenol. These results suggest that the effectiveness of the titania photocatalysts prepared by using these natural pigments as templates maybe depend on the structure and complexity of natural pigments [26]. Although there are no more facts to illustrate the relationship between the structures of natural pigments and the photocatalytic efficiency of titania using natural pigments-templates in this study, it can be concluded that anthocyanin from radish red, that is radish red pigment, may be an appropriate selection of natural pigment templates which allows new visible-light photocatalysts to be built directly.

3.3. FT-IR and XPS Investigation. To gain further insight of these phenomena, UV-Vis, FTIR, and XPS spectra of $\mathrm{MTiO}_{2} / \mathrm{RRP}, \mathrm{MTiO}_{2} / \mathrm{GB}$ along with $\mathrm{P} 25 \mathrm{TiO}_{2}$ were investigated. The FT-IR spectra of $\mathrm{MTiO}_{2} / \mathrm{RRP}, \mathrm{MTiO}_{2} / \mathrm{GB}$, and $\mathrm{P} 25 \mathrm{TiO}_{2}$ between 400 and $4000 \mathrm{~cm}^{-1}$ are presented in Figure 7. Interestingly, the peak of $\mathrm{MTiO}_{2} / \mathrm{RRP}$ in the range of $400-1000 \mathrm{~cm}^{-1}$ which is a contribution from the vibrations

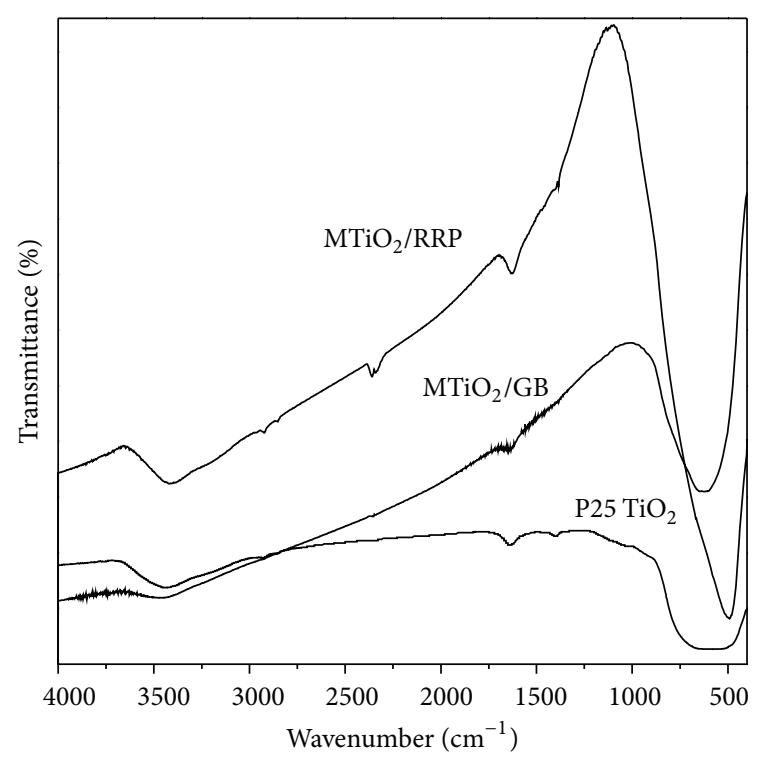

Figure 7: FT-IR spectra of $\mathrm{MTiO}_{2} / \mathrm{RRP}, \mathrm{MTiO}_{2} / \mathrm{GB}$, and P25. 


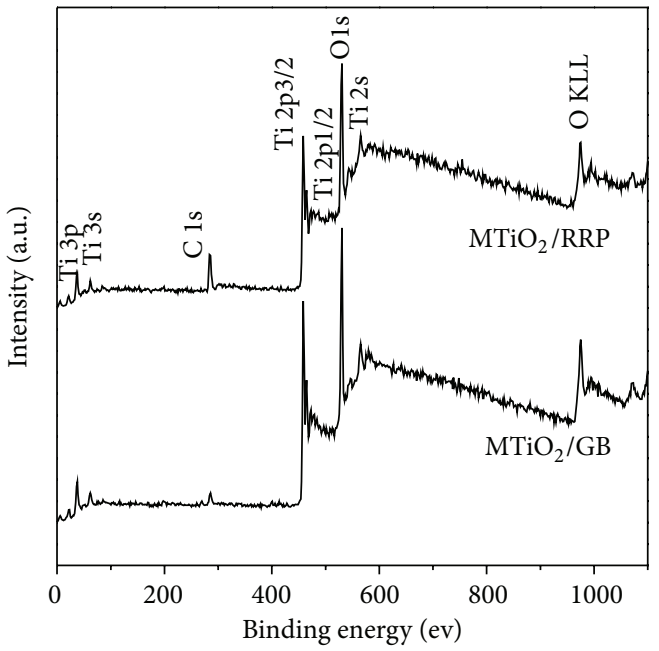

(a)

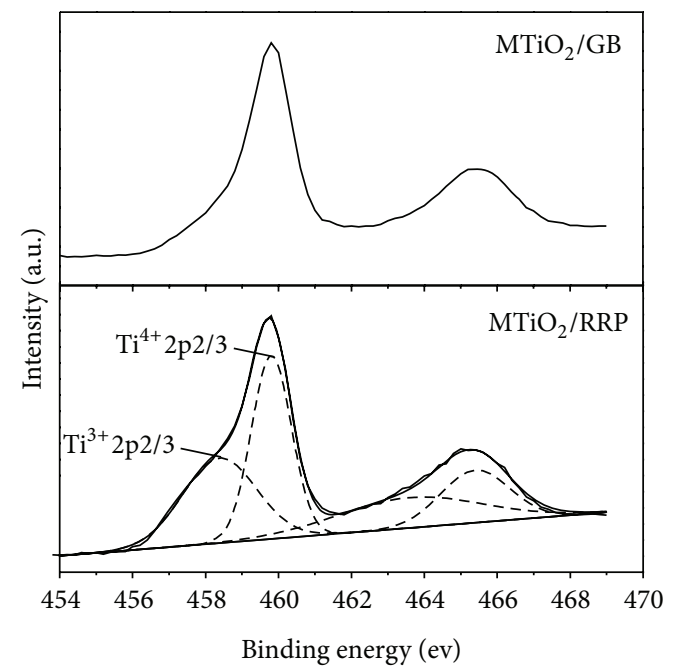

(c)

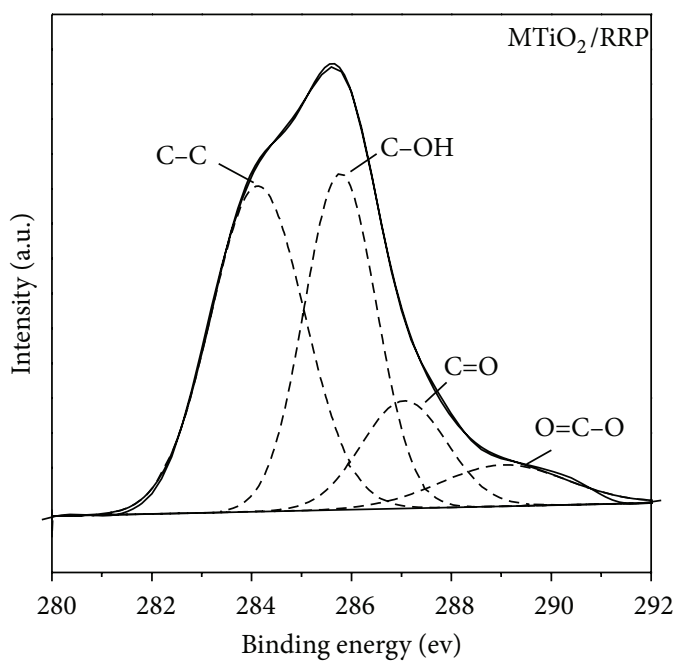

(b)

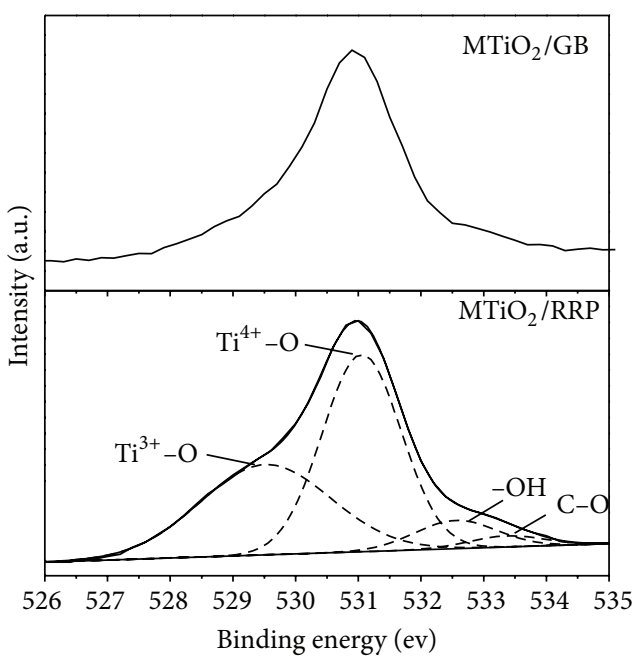

(d)

FIGURE 8: XPS survey spectrum of $\mathrm{MTiO}_{2}$ (a) and corresponding $\mathrm{C}$ 1s (b), Ti 2p (c), and O 1s (d) high-resolution XPS spectra.

of $\mathrm{Ti}-\mathrm{O}[21,27]$ is much sharper than that of $\mathrm{P} 25 \mathrm{TiO}_{2}$ and $\mathrm{MTiO}_{2} / \mathrm{GB}$. The two broad peaks at 1640 and 3200 $3420 \mathrm{~cm}^{-1}$ which can be attributed to the surface-adsorbed water and hydroxyl groups $[21,27,28]$ were also observed in $\mathrm{MTiO}_{2} / \mathrm{RRP}$. The surface hydroxyl groups have been recognized to play an important role in the photodegradation process through their interactions with photogenerated holes. In addition, $\mathrm{MTiO}_{2} / \mathrm{RRP}$ have two bands at 2925 and $2854 \mathrm{~cm}^{-1}$ assigned to the asymmetric and symmetric stretching vibrations of $-\mathrm{CH}_{2}-$ and $\mathrm{CH}_{3}$ - in alkyl chains, as well as a band in the $1300-1500 \mathrm{~cm}^{-1}$ assigned to $\mathrm{CH}_{2}$ bending vibrations, which are evident [29-31]. The peak at $1400 \mathrm{~cm}^{-1}$ is assigned to $\mathrm{CO}_{2}$ band [31]. Thus these indicate that during the heating process, dye template was decomposed and removed or physically adsorbed on the surface of $\mathrm{MTiO}_{2} / \mathrm{RRP}$ [31]. However, the FTIR data of -COOTi vibration referenced values of 1070,1710 and $1220 \mathrm{~cm}^{-1}$ [32, 33] were not found.
XPS measurements were also performed to elucidate the surface chemical composition and the oxidation state for the mesoporous $\mathrm{TiO}_{2}$. Figure $8(\mathrm{a})$ depicts the full survey spectra of $\mathrm{MTiO}_{2} / \mathrm{RRP}$ and $\mathrm{MTiO}_{2} / \mathrm{GB}$ samples. One can see that in both samples the elements of $\mathrm{Ti}$ and $\mathrm{O}$ can be clearly identified, with the binding energies of Ti2p and O1s electrons at approximately $459.1 \mathrm{eV}$ and $529.8 \mathrm{eV}$, respectively. Moreover, it is interestingly found that the carbon signal with the binding energies of Cls electrons at approximately $285 \mathrm{eV}$ is obviously stronger in $\mathrm{MTiO}_{2} / \mathrm{RRP}$ than in $\mathrm{MTiO}_{2} / \mathrm{GB}$. This indicates that the surface of $\mathrm{MTiO}_{2} / \mathrm{RRP}$ adsorbs more carbon likely from the organic precursors and template used to prepare the $\mathrm{TiO}_{2}$, not adventitious hydrocarbon from the XPS instrument itself. To analyze the state of the carbon element in $\mathrm{MTiO}_{2} / \mathrm{RRP}$, the Cls high-resolution XPS survey was conducted and the typical spectra are shown in Figure 8(b). The Cls XPS curves of $\mathrm{MTiO}_{2} / \mathrm{RRP}$ can be fitted to four peaks located at $284,285.8,287$, and $289.2 \mathrm{eV}$ by 


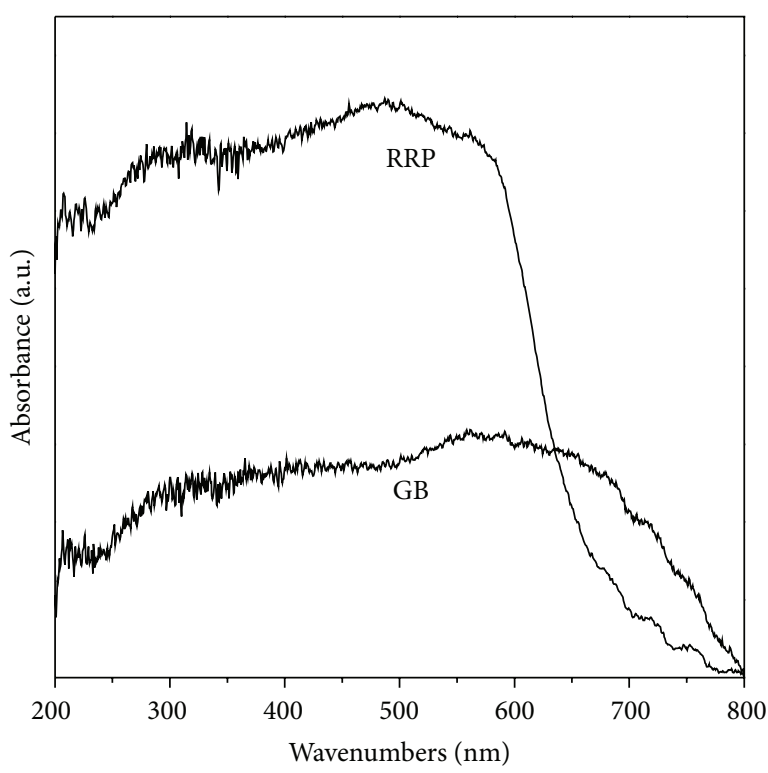

(a)

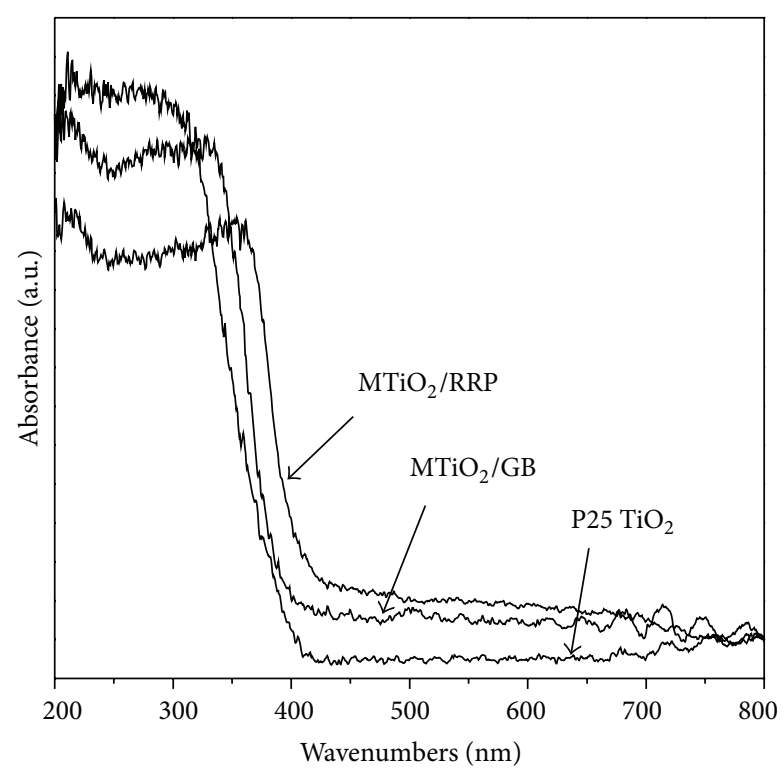

(b)

Figure 9: Comparison of absorption spectra of natural pigments RRP and GB (a); $\mathrm{MTiO}_{2} / \mathrm{RRP}, \mathrm{MTiO}_{2} / \mathrm{GB}$, and P25 (b).

using computer assisted Gaussian-Lorentzian peak model, respectively. The major peak at $284 \mathrm{eV}$ is related to carbon atoms in the $\mathrm{C}-\mathrm{C}, \mathrm{C}=\mathrm{C}$, and $\mathrm{C}-\mathrm{H}$ bonds [34]. In addition, the binding energies around 285.8, 287, and $289.2 \mathrm{eV}$ are assigned to the $\mathrm{C}-\mathrm{O}, \mathrm{C}=\mathrm{O}$ and $\mathrm{O}=\mathrm{C}-\mathrm{O}$ bonds, respectively [35]. The peak around $281 \mathrm{eV}$ resulting from $\mathrm{Ti}-\mathrm{C}$ bond was not observed, so carbon elements do not substitute oxygen atom in the lattice of anatase. These results are similar to those obtained by using commercial synthetic dyes in our previous work [15]. Figure 8(c) shows the high-resolution XPS spectra of Ti2p in $\mathrm{MTiO}_{2} / \mathrm{RRP}$ and $\mathrm{MTiO}_{2} / \mathrm{GB}$ samples, respectively. The Ti2p XPS curve of $\mathrm{MTiO}_{2} / \mathrm{RRP}$ has a similar shape to $\mathrm{MTiO}_{2} / \mathrm{GB}$ and could be resolved into two contributions corresponding to the different oxidation states of titanium. Each contribution consists of a doublet between the $2 \mathrm{p} 3 / 2$ and $2 \mathrm{p} 1 / 2$ peaks. A main doublet composed of two symmetric peaks situated at binding energies $459.8 \mathrm{eV}$ and $465.5 \mathrm{eV}$, in agreement with the literature [36], is assigned to Ti (IV). Another contribution is $\mathrm{Ti}$ (III) from $\mathrm{Ti}_{2} \mathrm{O}_{3}$ species; the symmetric peaks of the corresponding doublet are situated at binding energies $458.2 \mathrm{eV}$ and $463.7 \mathrm{eV}$, as reported in the literature [35]. Because the presence of reducing species ( $\mathrm{C}$ and $\mathrm{H})$ from organic radicals introduced by molecular precursors, $\mathrm{TiO}_{2}$ synthesized under the present conditions is likely to be oxygen deficient. To maintain the charge neutrality the presence of oxygen vacancies will lead to the formation of lower valent $\mathrm{Ti}$ cations [37]. The contributions of $\mathrm{Ti}^{3+}$ in $\mathrm{Ti}$ $2 \mathrm{p}$ on the surface of $\mathrm{MTiO}_{2} / \mathrm{RRP}$ and $\mathrm{MTiO}_{2} / \mathrm{GB}$ samples are $42.6 \%$ and $20.8 \%$, respectively. The result indicates that the $\mathrm{Ti}^{3+}$ ions content of $\mathrm{MTiO}_{2} / \mathrm{RRP}$ is evidently higher than that of $\mathrm{MTiO}_{2} / \mathrm{GB}$, which is due to the fact that a large amount of carbon around the $\mathrm{MTiO}_{2} / \mathrm{RRP}$ nanoparticles reduces $\mathrm{TiO}_{2}$ to form more $\mathrm{Ti}^{3+}$ ions. The Ols XPS curve of $\mathrm{MTiO}_{2} / \mathrm{RRP}$ has also a similar shape to $\mathrm{MTiO}_{2} / \mathrm{GB}$ and could be decomposed into several contributions in Figure 8(d). The main contribution is attributed to Ti-O $(531.0 \mathrm{eV})$ in $\mathrm{TiO}_{2}$ [38]. The other two kinds of oxygen contributions can be counted by the hydroxyl groups $(532.6 \mathrm{eV})$ and the C$\mathrm{O}$ bonds $(533.5 \mathrm{eV})$, respectively. In addition to the three peaks a shoulder is present at $529.5 \mathrm{eV}$ to the lower binding energy side, indicating the presence of different types of Ti$\mathrm{O}$ species. Thus, Ti 2p and $\mathrm{O}$ 1s spectra confirm the presence of $\mathrm{Ti}^{3+}$

3.4. UV/Vis Spectrum. Figure 9 shows the diffuse reflectance UV-Vis spectra of two dyes templates, RRP and GB, and their corresponding titania samples, $\mathrm{MTiO}_{2} / \mathrm{RRP}$ and $\mathrm{MTiO}_{2} / \mathrm{GB}$, as well as P25. Although RRP and GB exhibit absorption in the visible and UV region, RRP shows obviously higher absorption strength than GB in the range of 200-650 nm in Figure 9(a). Interestingly, as shown in Figure 9(b), the titania samples $\mathrm{MTiO}_{2} / \mathrm{RRP}$ also exhibited higher absorption strength than $\mathrm{MTiO}_{2} / \mathrm{GB}$ in visible region. Moreover, the band-gap-absorption onset of $\mathrm{MTiO}_{2} / \mathrm{RRP}$ at the edge of the UV and visible-light range shows an apparent red-shift compared to $\mathrm{MTiO}_{2} / \mathrm{GB}$ which only has slight shift in absorption spectra. Many investigations $[15,37]$ have found that organic impurities are still present in the $\mathrm{TiO}_{2}$, which could be responsible for the unusually high absorption of light. Regarding to $\mathrm{MTiO}_{2} / \mathrm{RRP}$, the incorporation of carbonaceous species formed during the calcination is a possible reason for the absorption tail in the visible-light region. On the one hand, carbonaceous species can effectively lower the band gap and make the absorption edge of $\mathrm{TiO}_{2}$ shift to the visiblelight range [15]. Therefore, the $\mathrm{MTiO}_{2} / \mathrm{RRP}$ photocatalyst with lower band gap energies could absorb more visible light. On the other hand, according to the literature [37], these 
carbon residues may occur in highly condensed and cokelike structure around $\mathrm{TiO}_{2}$ nanoparticles, so it could play the role of sensitizer to induce the visible-light absorption and response. By contrast, $\mathrm{P} 25 \mathrm{TiO}_{2}$ does not show any absorption in the visible region and considerable shift in absorption spectra as seen from Figure 9(b).

Due to the significant differences of the preparation processes between our sample and all of those which were prepared by using dyes as only photosensitizers, it is necessary to evoke some reasons why the mesoporous titanium dioxides $\left(\mathrm{MTiO}_{2} / \mathrm{RRP}\right)$ prepared by using radish red pigment as templates exhibited the better visible-light photocatalytic activities. The formation of mesoporous metal oxides via such a simple procedure suggests again that radish red pigment molecular, like commercial dyes used in our previous works $[14,15]$, is the ideal building blocks for supramolecular chemistry. Although the mechanism details of the formation of mesoporous materials are still far from understood, its highly crystalline framework and high specific surface area can provide more active sites and adsorb more reactive species, which could be one of the reasons that $\mathrm{MTiO}_{2} / \mathrm{RRP}$ affords the better activity toward photocatalytic reactions. On the other hand, both FTIR and XPS measurements in $\mathrm{MTiO}_{2} / \mathrm{RRP}$ indicate the presence of carbon residues such as carbonaceous species formed during calcinations. The incorporation of carbonaceous species may be responsible for the unusually high photodegradation yield of $\mathrm{MTiO}_{2} / \mathrm{RRP}$ under visible-light irradiation. Carbonaceous species can not only induce the visible-light absorption and response as a photosensitizer but also enhance the photoquantum efficiency. When the photocatalyst was excited under visible light, the carbonaceous species can also serve as an electron scavenger to protect the process of electron-hole recombination and that could be important because of the formation of low amount of free carriers [31]. In addition, it has also been reported [39] that $\mathrm{Ti}^{3+}$ surface states of $\mathrm{TiO}_{2}$ should act as a photocatalytic active site for the photodegradation of dye molecules and hydrogen generation via water-splitting. However, in our works $\mathrm{MTiO}_{2} / \mathrm{GB}$ with $20 \% \mathrm{Ti}^{3+}$ ions does not show any visible-light photocatalytic activity for RB. The fact suggests that high visible-light activity of $\mathrm{MTiO}_{2} / \mathrm{RRP}$ could mainly result from high carbonaceous species content rather than $\mathrm{Ti}^{3+}$ ion.

\section{Conclusions}

Visible-light responsive mesoporous anatase $\mathrm{TiO}_{2}$ with highly crystalline framework was successfully synthesized by facile combine sol-gel chemistry and self-assembly routes, directly using RRP, a natural food coloring agent as template. The excellent visible-light driven photocatalytic performance of $\mathrm{MTiO}_{2} / \mathrm{RRP}$ in the degradation of methyl orange and phenolic compounds are mainly attributed to its red shift of band-gap-absorption onset and visible-light response as a result of the incorporation of surface carbon species.

In summary, mesoporous titania prepared here was not modified with any transition metals or anions and show good visible-light photocatalytic activities for the degradation of aqueous phase pollutants. This approach is simpler and potentially more stable than conventional photosensitization. Furthermore, the new mesoporous titania materials synthesized using natural food coloring agents as templates may be less toxic than those prepared by the toxic dyes. We believe that the synthetic strategy demonstrated here could be extended to other mesoporous materials. This could open up new uses for mesoporous titania in applications such as treatment of polluted water, dye-sensitized solar cells, or other regions.

\section{Conflict of Interests}

The authors declare that there is no conflict of interests regarding the publication of this paper.

\section{Acknowledgment}

The work was supported by the National Natural Science Funding (China, nos. 21367024, 21063016, and U1033603).

\section{References}

[1] A. Kubacka, M. Fernández-García, and G. Colón, "Advanced nanoarchitectures for solar photocatalytic applications," Chemical Reviews, vol. 112, no. 3, pp. 1555-1614, 2012.

[2] N. Todorova, T. Vaimakis, D. Petrakis et al., "N and N,Sdoped $\mathrm{TiO}_{2}$ photocatalysts and their activity in $\mathrm{NO}_{x}$ oxidation," Catalysis Today, vol. 209, pp. 41-46, 2013.

[3] Z. Zheng, B. Huang, X. Qin, X. Zhang, Y. Dai, and M. H. Whangbo, "Facile in situ synthesis of visible-light plasmonic

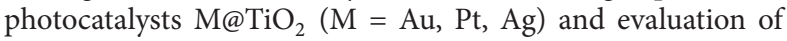
their photocatalytic oxidation of benzene to pheno l," Journal of Material Chemistry, vol. 21, no. 25, pp. 9079-9087, 2011.

[4] M. Liang and J. Chen, "Arylamine organic dyes for dyesensitized solar cells," Chemical Society Reviews, vol. 42, no. 8 , pp. 3453-3488, 2013.

[5] A. Venkateswararao, K. R. Justin Thomas, C. P. Lee, C. T. Li, and K. C. Ho, "Organic dyes containing carbazole as donor and pLinker: optical, electrochemical, and photovoltaic properties," ACS Applied Material \& Interfaces, vol. 6, no. 4, pp. 2528-2539, 2014.

[6] P. Chowdhury, J. Moreira, H. Gomaa, and A. K. Ray, "Visiblesolar-light-driven photocatalytic degradation of phenol with dye-sensitized $\mathrm{TiO}_{2}$ : parametric and kinetic study," Industrial and Engineering Chemistry Research, vol. 51, no. 12, pp. 45234532, 2012.

[7] H. Hubert, B. Michael, M. Peter, and T. Glztael, "Biophotovoltaics : natural pigments in dye-sensitized solar cells," Applied Energy, vol. 115, no. 3, pp. 216-225, 2014.

[8] H. Zhou, L. Wu, Y. Gao, and T. Ma, "Dye-sensitized solar cells using 20 natural dyes as sensitizers," Journal of Photochemistry and Photobiology A: Chemistry, vol. 219, no. 2-3, pp. 188-194, 2011.

[9] N. A. Ludin, A. M. A. Mahmoud, A. B. Mohamad, A. A. H. Kadhum, K. Sopian, and N. S. A. Karim, "Review on the development of natural dye photosensitizer for dye-sensitized solar cells," Renewable and Sustainable Energy Reviews, vol. 31, pp. 386-396, 2014. 
[10] G. Calogero, J.-H. Yum, A. Sinopoli, G. di Marco, M. Grätzel, and M. K. Nazeeruddin, "Anthocyanins and betalains as lightharvesting pigments for dye-sensitized solar cells," Solar Energy, vol. 86, no. 5, pp. 1563-1575, 2012.

[11] A. Zyoud, N. Zaatar, I. Saadeddin et al., "Alternative natural dyes in water purification: anthocyanin as $\mathrm{TiO}_{2}$-sensitizer in methyl orange photo-degradation," Solid State Sciences, vol. 13, no. 6, pp. 1268-1275, 2011.

[12] C. F. J. Faul and M. Antonietti, "Facile synthesis of optically functional, highly organized nanostructures: dye-surfactant complexes," Chemistry, vol. 8, no. 12, pp. 2764-2768, 2002.

[13] Y. Xu, Y. Cui, D. Jiang, D. Wu, and Y. H. Sun, "Dye-templating nonsurfactant synthesis of mesoporous silica," Microporous and Mesoporous Materials, vol. 109, no. 1-3, pp. 335-341, 2008.

[14] W.-J. Gong, H.-W. Tao, G.-L. Zi et al., "Visible light photodegradation of dyes over mesoporous titania prepared by using chrome azurol S as template," Research on Chemical Intermediates, vol. 35, no. 6-7, pp. 751-760, 2009.

[15] J. Wang, J. Wang, Q. Sun et al., "UV and solar light degradation of dyes over mesoporous crystalline titanium dioxides prepared by using commercial synthetic dyes as templates," Journal of Materials Chemistry, vol. 19, no. 36, pp. 6597-6604, 2009.

[16] J.-M. Kong, L.-S. Chia, N.-K. Goh, T.-F. Chia, and R. Brouillard, "Analysis and biological activities of anthocyanins," Phytochemistry, vol. 64, no. 5, pp. 923-933, 2003.

[17] T. Otsuki, H. Matsufuji, M. Takeda, M. Toyoda, and Y. Goda, "Acylated anthocyanins from red radish (Raphanus sativus L.)," Phytochemistry, vol. 60, no. 1, pp. 79-87, 2002.

[18] T. Sreethawong, Y. Suzuki, and S. Yoshikawa, "Photocatalytic evolution of hydrogen over nanocrystalline mesoporous titania prepared by surfactant-assisted templating sol-gel process," Catalysis Communications, vol. 6, no. 2, pp. 119-124, 2005.

[19] J.-Y. Zheng, J.-B. Pang, K.-Y. Qiu, and Y. Wei, "Synthesis of mesoporous titanium dioxide materials by using a mixture of organic compounds as a non-surfactant template," Journal of Materials Chemistry, vol. 11, no. 12, pp. 3367-3372, 2001.

[20] J. Wang, H. Fang, Y. Li, J. Li, and Z. Yan, "Liquid phase oxidation of $p$-chlorotoluene to $p$-chlorobenzaldehyde over cobalt-doped mesoporous titania with a crystalline framework," Journal of Molecular Catalysis A: Chemical, vol. 250, no. 1-2, pp. 75-79, 2006.

[21] J. C. Yu, L. Zhang, Z. Zheng, and J. Zhao, "Synthesis and characterization of phosphated mesoporous titanium dioxide with high photocatalytic activity," Chemistry of Materials, vol. 15, no. 11, pp. 2280-2286, 2003.

[22] Y. Wu, S. Liu, Y. Zuo, J. Li, and J. Wang, "Photodegradation of some dyes over Ce/FSM-16 catalyst under solar light," Catalysis Letters, vol. 119, no. 3-4, pp. 245-251, 2007.

[23] M. Yoshinaga, M. Tanaka, and M. Nakatani, "Changes in anthocyanin content and composition of developing storage root of purple-fleshed sweet potato (Ipomoea batatas (L.) Lam)," Breeding Science, vol. 50, no. 1, pp. 59-64, 2000.

[24] J.-M. Yoon, M.-H. Cho, J.-E. Park, Y.-H. Kim, T.-R. Hahn, and Y.-S. Paik, "Thermal stability of the pigments hydroxysafflor yellow A, safflor yellow B, and precarthamin from safflower (Carthamus Tinctorius)," Journal of Food Science, vol. 68, no. 3, pp. 839-843, 2003.

[25] W. Winotapun, P. Opanasopit, T. Ngawhirunpat, and T. Rojanarata, "One-enzyme catalyzed simultaneous plant cell disruption and conversion of released glycoside to aglycone combined with in situ product separation as green one-pot production of genipin from gardenia fruit," Enzyme and Microbial Technology, vol. 53, no. 2, pp. 92-96, 2013.

[26] K.-C. Chen, J.-Y. Wu, D.-J. Liou, and S.-C. J. Hwang, "Decolorization of the textile dyes by newly isolated bacterial strains," Journal of Biotechnology, vol. 101, no. 1, pp. 57-68, 2003.

[27] T. Peng, D. Zhao, H. Song, and C. Yan, "Preparation of lanthanadoped titania nanoparticles with anatase mesoporous walls and high photocatalytic activity," Journal of Molecular Catalysis A: Chemical, vol. 238, no. 1-2, pp. 119-126, 2005.

[28] M. Zheng, M. Gu, Y. Jin, and G. Jin, "Preparation, structure and properties of $\mathrm{TiO}_{2}-\mathrm{PVP}$ hybrid films," Materials Science and Engineering B: Solid-State Materials for Advanced Technology, vol. 77, no. 1, pp. 55-59, 2000.

[29] X. U. Zhao, Z. Li, Y. Chen, L. Shi, and Y. Zhu, "Solid-phase photocatalytic degradation of polyethylene plastic under UV and solar light irradiation," Journal of Molecular Catalysis A: Chemical, vol. 268, no. 1-2, pp. 101-106, 2007.

[30] J. Yang, H. Bai, X. Tan, and J. Lian, "IR and XPS investigation of visible-light photocatalysis-Nitrogen-carbon-doped $\mathrm{TiO}_{2}$ film," Applied Surface Science, vol. 253, no. 4, pp. 1988-1994, 2006.

[31] M. Janus, M. Inagaki, B. Tryba, M. Toyoda, and A. W. Morawski, "Carbon-modified $\mathrm{TiO}_{2}$ photocatalyst by ethanol carbonisation," Applied Catalysis B: Environmental, vol. 63, no. 3-4, pp. 272-276, 2006.

[32] S. Doeuff, M. Henry, C. Sanchez, and J. Livage, "Hydrolysis of titanium alkoxides: modification of the molecular precursor by acetic acid," Journal of Non-Crystalline Solids, vol. 89, no. 1-2, pp. 206-216, 1987.

[33] D. Jiang, Y. Xu, D. Wu, and Y. Sun, "Visible-light responsive dyemodified $\mathrm{TiO}_{2}$ photocatalyst," Journal of Solid State Chemistry, vol. 181, no. 3, pp. 593-602, 2008.

[34] H. Yang, S. Wu, Y. Duan, X. Fu, and J. Wu, "Surface modification of CNTs and enhanced photocatalytic activity of $\mathrm{TiO}_{2}$ coated on hydrophilically modified CNTs," Applied Surface Science, vol. 258, no. 7, pp. 3012-3018, 2012.

[35] Y. Park, W. Kim, H. Park, T. Tachikawa, T. Majima, and W. Choi, "Carbon-doped $\mathrm{TiO}_{2}$ photocatalyst synthesized without using an external carbon precursor and the visible light activity," Applied Catalysis B: Environmental, vol. 91, no. 1-2, pp. 355-361, 2009.

[36] N. C. Raut, T. Mathews, P. Chandramohan, M. P. Srinivasan, S. Dash, and A. K. Tyagi, "Effect of temperature on the growth of $\mathrm{TiO}_{2}$ thin films synthesized by spray pyrolysis: structural, compositional and optical properties," Materials Research Bulletin, vol. 46, no. 11, pp. 2057-2063, 2011.

[37] P. Górska, A. Zaleska, E. Kowalska et al., " $\mathrm{TiO}_{2}$ photoactivity in vis and UV light: the influence of calcination temperature and surface properties," Applied Catalysis B: Environmental, vol. 84, no. 3-4, pp. 440-447, 2008.

[38] N. K. Dey, M. J. Kim, K.-D. Kim et al., "Adsorption and photocatalytic degradation of methylene blue over $\mathrm{TiO}_{2}$ films on carbon fiber prepared by atomic layer deposition," Journal of Molecular Catalysis A: Chemical, vol. 337, no. 1-2, pp. 33-38, 2011.

[39] X. Liu, H. Xu, and L. R. Grabstanowicz, “ $\mathrm{Ti}^{3+}$ self-doped $\mathrm{TiO}_{2-x}$ anatase nanoparticles via oxidation of $\mathrm{TiH}_{2}$ in $\mathrm{H}_{2} \mathrm{O}_{2}$," Catalysis Today, vol. 225, pp. 80-89, 2014. 

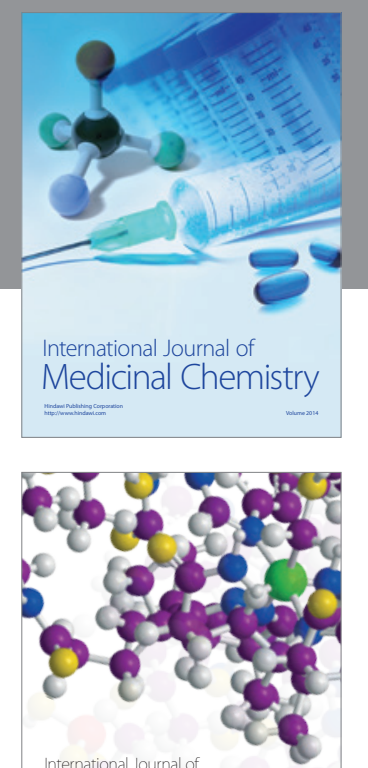

\section{Carbohydrate} Chemistry

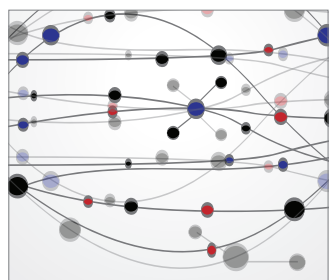

The Scientific World Journal
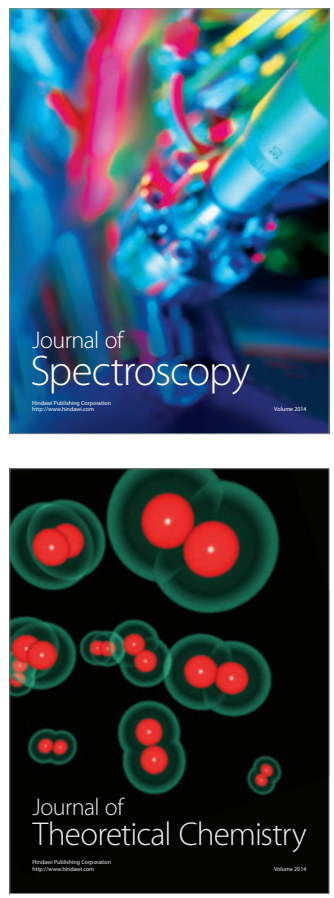
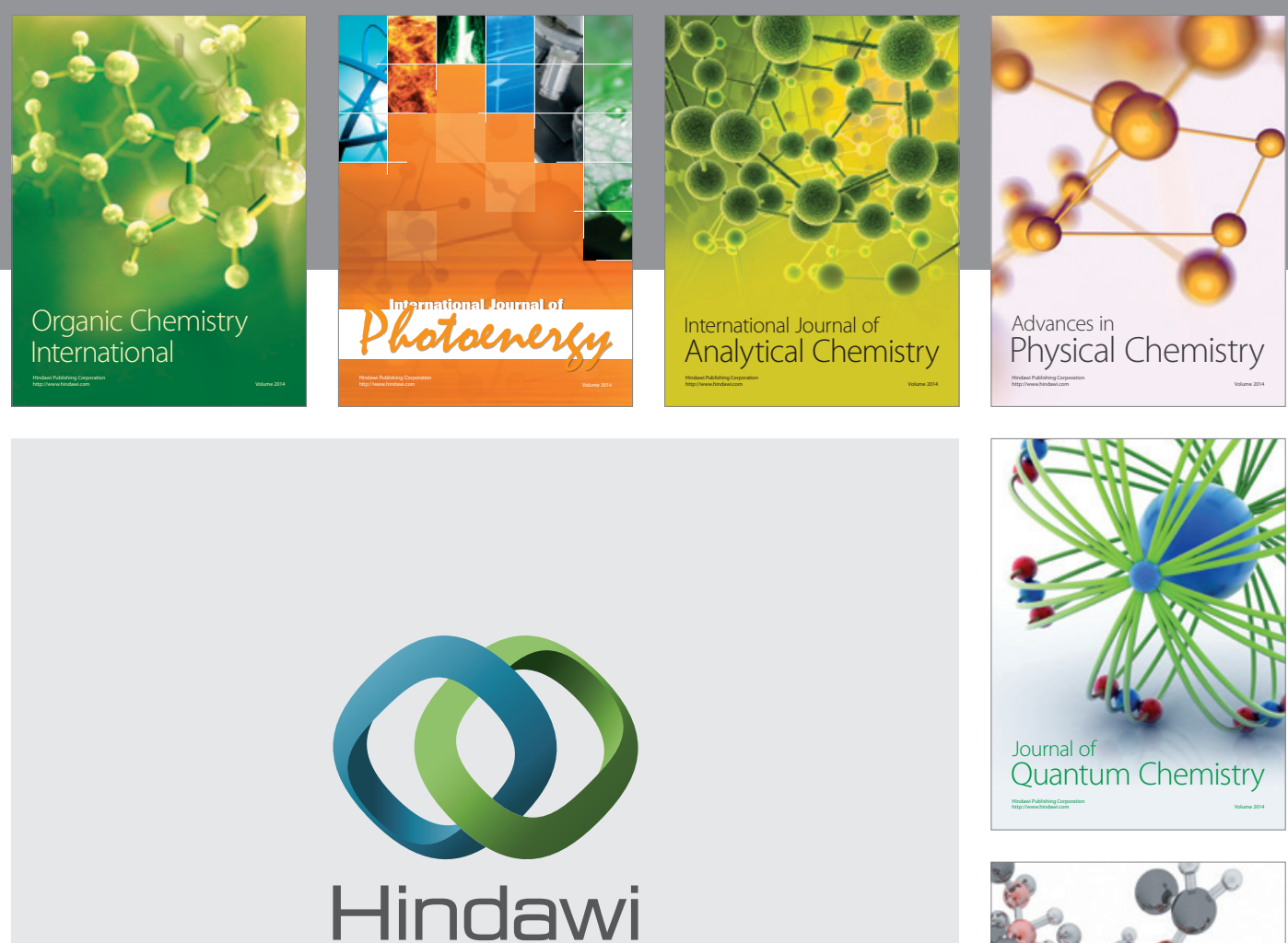

Submit your manuscripts at

http://www.hindawi.com

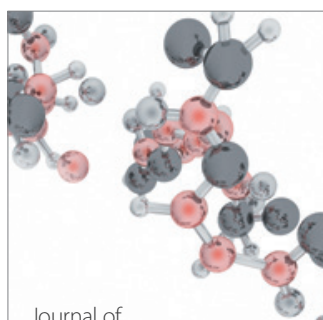

Analytical Methods

in Chemistry

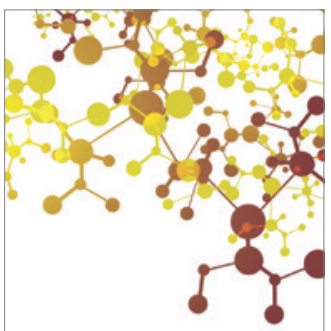

Journal of

Applied Chemistry

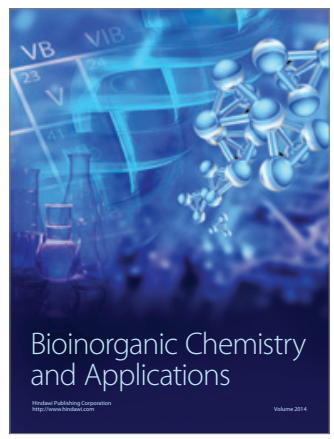

Inorganic Chemistry
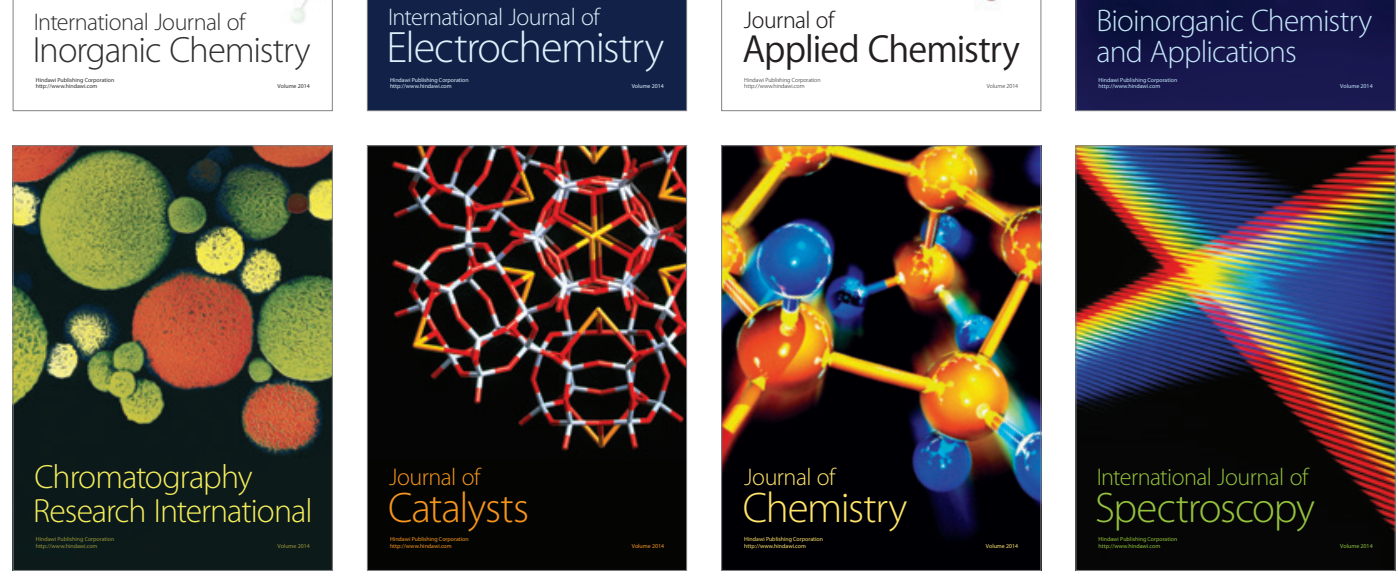